associated with past or present duodenal ulceration may be a secondary lesion, due either to gastric stasis (Johnson, 1955) or to bile reflux (Capper, 1967). It might, therefore, be reasonable to hope that cure of the duodenal ulcer by vagotomy and pyloroplasty would be followed by healing of the gastric ulcer as well, and Douglas and Duthie (1971) reported no recurrences in 35 patients with combined ulcers treated in this way. In our series, however, 3 out of the 29 patients in this group suffered a recurrence. Kraft et al. (1971) also reported a 10\% recurrence rate for combined ulcers compared with only $3 \%$ for isolated gastric ulcers treated by vagotomy and pyloroplasty, while in the series of 72 patients with gastric ulcer similarly treated by Burge et al. (1970) the three who developed further gastric ulceration all had associated duodenal lesions. We therefore feel that for combined ulcers vagotomy and antrectomy is a better alternative to gastrectomy as a primary operation than vagotomy and pyloroplasty.

High Ulcers.-Vagotomy and pyloroplasty gave satisfactory long-term results in all but 1 of our 21 patients with high ulcers. Most of these ulcers were on or close to the cardia and, as was often recorded in the operation notes, gastrectomy with removal of the ulcer would have been difficult or extensive. In some cases a Pauchet manoeuvre would have helped to minimize the extent of resection, but there would probably have been a greater risk of operative death or of long-term nutritional side effects than with vagotomy and pyloroplasty. A third possibility is the Kelling-Madlener operation, in which the ulcer (after biopsy) is left in situ and a distal gastrectomy performed. Mauer (1951) reported good results with this operation, and it has been suggested as a possible alternative to gastrectomy by Farris and Smith (1966). We believe, however, that in patients with high ulcers vagotomy and pyloroplasty with biopsy of the ulcer edge is probably the wisest choice.

Bleeding Gastric Ulcers.-Fourteen of our patients presented with acute haemorrhage and this may well have been regarded as an indication for a shorter and less traumatic procedure than gastrectomy. In 13 both the immediate and long-term results were satisfactory; the remaining patient was bleeding from the ulcer base on the pancreas, and re-bled even after gastrectomy. Unless the ulcer is so situated that gastrectomy is relatively easy, we prefer vagotomy and pyloroplasty, with undersewing of the ulcer, as a life-saving procedure in the presence of haemorrhage. In a series of 77 cases of bleeding peptic ulcer (26 of which were gastric) reviewed by Foster et al. (1965) the mortality for this form of treatment was $12 \%$ compared with $22 \%$ for gastrectomy, although the incidence of further haemorrhage was the same.

\section{Conclusion}

We believe that for an easily resectable gastric ulcer a Billroth I gastrectomy is the treatment of choice, with the addition of vagotomy if duodenal ulceration is also present. However, for the high and difficult gastric ulcer and for the bleeding gastric ulcer vagotomy and pyloroplasty is an acceptable alternative to partial gastrectomy. But as with all forms of conservative surgical treatment of gastric ulcer the possibility of malignancy must be remembered and biopsy should never be omitted. A fourquadrant specimen has been advocated by many authors; we prefer excision of a specimen from the rim of the ulcer but not including the base. This can readily be achieved even with the difficult high posterior ulcer via an anterior gastrotomy, the resulting defect being closed with catgut from inside the stomach.

Requests for reprints should be sent to $\mathrm{Mr}$. J. Alexander Williams.

\section{References}

Burge, H. (1966). Annals of the Royal College of Surgeons of England, 38, 349. Burge, H., Gill, A. M., McLean, C., and Stedeford, R. (1970). British Medical fournal, 3,376

Capper, W. M. (1967). Annals of the Royal College of Surgeons of England, 40,21 . Douglas, M. C., and Duthie, H. L. (1971). British fournal of Surgery, 58,
721 .

Duthie, H. L., Moor, K. T. H., Bardsley, D., and Clark, R. G. (1970).

Farris, M. J., and Smith, G. K. (1966). Surgical Clinics of North America, 46, 329.

Forrest, A. P. M. (1969). In After Vagotomy, ed. J. A. Williams, and A. Cox, chap. 26. London, Butterworths.

Foster, J. M., Hickok, D. F., and Dunphy, J. E. (1965). Annals of Surgery,

161, 968.

Goligher, J. C., et al. (1972). British Medical fournal, 1, 7.

Hendry, W. G., and Bahrani, Z. A. (1965). British Fournal of Surgery, 52, 588.

Johnson, H. D. (1955). Lancet, 1, 266.

Kraft, R. O., Myers, J., Overton, S., and Fry, W. J. (1971). American fournal of Surgery, 121, 122.

McNeill, A. D., McAdam, W. A. F., and Hutchison, J. S. F. (1969). Surgery, Gynaecology and Obstetrics with International Abstracts of Surgery, 128, 91.

Mauer, M. (1951). Bruns' Beiträge zur klinischen Chirurgie, 182, 266.

Sawyers, J. L., Scott, H. W., and Graham, C. (1971). American fournal of Surgery, 121, 119.

\title{
Vagotomy for Gastric Ulcer
}

\section{TERENCE KENNEDY， J. MALCOLM KELLY, J. DOUGLAS GEORGE}

British Medical fournal, 1972, 2, 371-373

\section{Summary}

Out of a series of 75 patients who were treated by vagotomy and drainage for gastric ulcer 66 have been followed up for one to seven years (average three-and-a-half years). Four recurrent gastric ulcers occurred among the 33 cases of ulcer of the lesser curve or body with no antral or duodenal lesion (type I). Among the 42 patients with an antral ulcer or an associated active or healed

Royal Victoria Hospital, Belfast

TERENCE KENNEDY, M.D., F.R.C.s., Consultant Surgeon

J. MALCOLM KELLY, M.B., B.S., F.R.C.S., Senior Registrar in Surgery

J. DOUGLAS GEORGE, M.CH., F.R.C.S., Senior Registrar in Surgery

(At present Consultant Surgeon, Norfolk and Norwich Hospital, Norwich) pyloric or duodenal lesion (type II or III) there was only one recurrence. The recurrence rate for men was $\mathbf{5} \%$ and for women $12 \%$. One patient died two years after operation from cancer which may have originated in the stomach. The clinical results in patients without recurrences were generally satisfactory.

Vagotomy, preferably selective, with drainage is a satisfactory operation in gastric ulcers of types II and III. For ulcers of type I, gastrectomy is to be preferred except in selected cases.

\section{Introduction}

Most surgeons in Britain today accept vagotomy, associated with a drainage procedure, as the treatment of choice for duo- 
denal ulcer. It is a safer operation than partial gastrectomy, with less devastating side effects. Vagotomy and pyloroplasty has also been advocated for the treatment of gastric ulcer (Hendry and Bahrani, 1965; Burge, 1966; Farris and Smith, 1966; de Miguel, 1970; Kraft et al., 1971; Sawyers et al., 1971) but it has not been widely accepted as an improvement on the standard operation-namely, Billroth I partial gastrectomy.

Our interest in conservative surgery was stimulated by the case of a man aged 82 whose high, lesser curve ulcer healed and remained healed for nine years after an associated pyloric stenosis was relieved by pyloroplasty. Unfortunately, of five further patients three developed recurrence within a few months and only one had a long-term remission. This $50 \%$ recurrence rate, supported by the similar experience of Woodward et al. (1967), Stemmer et al. (1968), and Kraft et al. (1971), led us to add vagotomy in all cases.

\section{Material}

We report here a retrospective study of a series of 75 patients with gastric ulcer who were treated by vagotomy and drainage during the years 1962-71. Forty-eight were men, with an age range of 31 to 88 (average 55) years; 27 were women, with an age range of 30 to 79 (average 53) years.

Before operation a test meal with histamine (or latterly pentagastrin) stimulation was performed on 51 patients and a study of gastric emptying by a dye dilution technique (George, 1968) was made on 16.

Vagotomy was truncal in 34 cases, selective in 40 , and highly selective in one. Drainage was by pyloroplasty of a modified Finney type in 70 patients and by posterior gastrojejunostomy in five. Biopsy of the ulcer edge was performed as a routine; in the latter part of the series specimens were taken from four quadrants. Insulin tests were performed, usually in the early postoperative period, on 60 patients, with positive results by Hollander's criteria in three. Forty-two patients had either active duodenal ulcer or pyloroduodenal scarring in association with their gastric ulcer (type II of Johnson et al. (1964) ) or had an ulcer in the pyloric or prepyloric region (type III). The remaining 33 patients had ulcers at or above the angulus with no pyloric or duodenal lesion (type I).

Follow-up was by personal interview, but no attempt was made to conduct this on a blind basis. Two patients were assessed by letter only. Each patient was given a clinical grading according to a modified Visick system: grade I, no symptoms-a perfect result; grade II, mild symptoms-not troublesome; grade III, moderate symptoms-causing some disability; grade IV, recurrent ulcer, or severe symptoms, or need for further operation.

Recurrences were confirmed by barium meal, by gastroscopy, and by operation.

\section{Results}

One patient, a man aged 65 , died eight weeks after operation with respiratory failure. The remainder all left hospital well, but seven died in the follow-up period. One man aged 88 and another aged 82 died at home, and in neither case was the precise cause of death determined. One man aged 70 died from a stroke and a man of 54 died with alcoholic cirrhosis. Three patients died from cancer-one woman with carcinoma of the kidney, one woman with carcinoma of the colon, and one man with carcinoma, probably of the stomach; this case is discussed more fully below.

Follow-up data, including those of six patients who subsequently died, are available on 66 patients after one year, on 60 after two years, on $\mathbf{4 4}$ after three years, on 31 after four years, and on 23 after five to seven years, the average follow-up time being three-and-a-half years. In nine patients no follow-up data are available-two died within the first year, two could not be traced, and five have not yet reached their first anniversary. There were five recurrent ulcers, an overall rate of $7.5 \%$ in those followed up-one was found during the first year, two during the second year, and two during the third year after operations. All these recurrences were gastric ulcers. There were no recurrences among the five cases in which gastrojejunostomy was the method of drainage. Three recurrences were in women $(12 \%$ of those followed up) and two were in men (5\%) (Table I).

Four patients had recurrences after operation for type I ulcers (13\% of those followed up) (Table II). Three of these four had a preoperative test meal, which showed a low level of acid, in no case exceeding $10 \mathrm{mEq}$ in the hour after stimulation. Ten-day postoperative insulin tests were positive in two of this group, but had become negative when repeated at the time of recurrence (Table III). In women with type I ulcers the recurrence rate was $20 \%$.

TABLE I-Sex Distribution

\begin{tabular}{|c|c|c|c|c|}
\hline Sex & & Total Cases & Followed 1-7 Years & Recurrences \\
\hline $\begin{array}{l}\text { Males .. } \\
\text { Females }\end{array}$ & $\because$. & $\begin{array}{l}48 \\
27\end{array}$ & $\begin{array}{l}41 \\
25\end{array}$ & $\begin{array}{l}2(5 \%) \\
3(12 \%)\end{array}$ \\
\hline
\end{tabular}

TABLE II-Type of Ulcer

\begin{tabular}{cc|c|c|c}
\hline \multicolumn{2}{r|}{ Ulcer Type } & No. of Cases & Followed 1-7 Years & Recurrences \\
\hline II ... III.. &.. & 33 & 30 & $4(13 \%)$ \\
\hline
\end{tabular}

TABLE III-Details in Cases of Recurrence after Operation

\begin{tabular}{|c|c|c|c|c|c|c|}
\hline \multirow[t]{2}{*}{ Age } & \multirow[t]{2}{*}{ Sex } & \multirow[t]{2}{*}{ Ulcer Type } & \multirow{2}{*}{$\begin{array}{l}\text { Preoperative } \\
\text { Max. } \\
\text { Acid/Hour } \\
\text { (mEq) }\end{array}$} & \multicolumn{2}{|c|}{$\begin{array}{c}\text { Postoperative } \\
\text { Insulin Test. } \\
\text { Hollander Criteria }\end{array}$} & \multirow{2}{*}{$\begin{array}{l}\text { Time of } \\
\text { Recur- } \\
\text { rence }\end{array}$} \\
\hline & & & & Early & Late & \\
\hline $\begin{array}{l}60 \\
32 \\
36 \\
64 \\
59\end{array}$ & $\begin{array}{l}\mathbf{F} . \\
\mathbf{F} . \\
\mathbf{F} . \\
\mathbf{M} .\end{array}$ & $\begin{array}{l}\text { I } \\
\text { I } \\
\text { I } \\
\text { I } \\
\text { III }\end{array}$ & $\begin{array}{r}6 \cdot 1 \\
9 \cdot 6 \\
7 \cdot 4 \\
43 \cdot 2\end{array}$ & $\begin{array}{l}\text { Negative } \\
\text { Negative } \\
\text { Positive } \\
\text { Positive } \\
\text { Negative }\end{array}$ & $\begin{array}{l}\text { Negative } \\
\text { Negative } \\
\text { Negative }\end{array}$ & $\begin{array}{ll}1 \frac{1}{2} & \text { years } \\
1 & = \\
3 & m \\
2 & m \\
1 \frac{1}{2} & m\end{array}$ \\
\hline
\end{tabular}

Only one of the patients with type II or III ulcers $(3 \%$ of those followed up) developed a recurrence. He was a man aged 59 with a large prepyloric ulcer. Preoperative acid levels were high, $43.2 \mathrm{mEq} /$ hour after pentagastrin stimulation, and an early postoperative insulin test was negative. Failure may have been due to a baggy antral pouch produced by shortening of the lesser curvature, due to contracture of scar tissue, but antral stasis as a cause for recurrence was not confirmed by assay of the fasting gastrin level, which was less than $100 \mathrm{pg} / \mathrm{ml}$-a normal level. Unfortunately acute haemorrhage demanded reoperation before a further insulin test could be performed.

In addition to these five recurrences there was one man, aged 59 , with a prepyloric ulcer, histologically benign, who died two years later with upper abdominal carcinoma. It was impossible to decide whether this was of gastric or pancreatic origin, as both organs were involved. In spite of the negative biopsy report at the time of vagotomy, it must be assumed that this was, in fact, a missed cancer.

Apart from these failures, all grade IV, one patient was given Visick grade IV and another grade III on account of severe and intractable diarrhoea. Of the remainder, 39 patients achieved Visick I grading, being absolutely symptom-free at their most recent interview, and 19 were given Visick grade II, usually because of mild dumping symptoms.

\section{Discussion}

The reputation of Billroth I gastrectomy for gastric ulcer, with a low mortality rate and a low incidence of recurrent ulcer, is so well established that vagotomy with drainage must give 
excellent results if it is to be widely adopted. Duthie (1970), in a collected series, found that mortality was $1.8 \%$ after gastrectomy for gastric ulcer and $1.4 \%$ after vagotomy and pyloroplasty. The advantages and disadvantages of vagotomy are thus likely to become apparent in recurrence rates and in later nutritional and other side effects rather than in mortality statistics.

No one has yet given a satisfactory explanation of the fact that benign gastric ulcers usually heal after vagotomy and pyloroplasty. The concept of antral stasis associated with pyloric stenosis (Dragstedt, 1956) or pyloric channel syndrome (Burge, 1966) as a cause of gastric ulcer cannot explain every case. Bile regurgitation has also been incriminated as a causative factor (Capper, 1967) but it is difficult to understand how this can be influenced by vagotomy and pyloroplasty. In our experience of type I gastric ulcers bile was found in excess in the stomach in one-third of the patients, whereas delayed gastric emptying seemed to be the main aetiological factor in the remaining two-thirds (George et al., 1967).

It is not likely that all gastric ulcers arise in the same way. Johnson et al. (1964) showed that in cases of type I acid output is usually low and there is an excess of blood group $\mathrm{A}$, whereas in cases of type II or III acid output is usually high, there is a preponderance of blood group $\mathrm{O}$, and the behaviour closely resembles that of duodenal ulcer.

Ulcers of types II and III can be conveniently considered together, and we feel that they should be treated as duodenal ulcers, by vagotomy and drainage. Billroth I gastrectomy for patients with type II ulcers carries a significant risk of recurrence in the duodenum unless vagotomy is added, and this combined operation unfortunately exposes the patient to the undesired long-term sequelae of both operations. Satisfactory results of vagotomy and drainage in type II or III ulcers have been reported by Douglas and Duthie (1971) and Wasunna et al. (1971), and although Kraft et al. (1971) reported a recurrence rate of $10 \%$ for combined gastric and duodenal ulcer (compared with $3 \%$ for "isolated" gastric ulcer) this result may well have been due to incompleteness of the vagotomy. Our own experience of one recurrence in 36 cases of type II or III ulcer falls well within the acceptable limits.

It is type I ulcers that present the real challenge. They often occur in frail, elderly patients-just the type of individual in whom surgeons try to avoid gastrectomy on account of the longterm nutritional side effects. These ulcers are often high, and resection may present considerable technical difficulties. It is surely in just this group of patients that one would like to use vagotomy and drainage.

If vagotomy and pyloroplasty is to succeed there should logically be either a high level of acidity or delay in gastric emptying, or both. In three of our four patients with recurrences of type I ulcers the preoperative acid output was low and in the fourth it was not measured. At the time that these patients were treated no satisfactory test of the rate of gastric emptying was available for routine clinical use. We now avoid vagotomy in patients with type I ulcers with both hypoacidity and rapid gastric emptying. Women, especially those with type I ulcers, seem to fare worse then men; perhaps these differences simply reflect the less satisfactory results of all forms of gastric surgery in the female.

The risk that any gastric ulcer may be malignant is a powerful argument against leaving it in situ. When vagotomy and drainage is performed biopsy is mandatory and should include at least four quadrants; many surgeons now advocate excision of the entire ulcer circumference (Duthie et al., 1970). Three of our patients have died with cancer in the follow-up period. In two the tumour was certainly unrelated, but in the third there was a suspicion that the ulcer, which healed after vagotomy, may have been associated with a cancer of the stomach. We now avoid vagotomy and drainage whenever there is any clinical or operative doubt of the benign nature of a gastric ulcer, or where acid levels are very low, regardless of the results of biopsy of the ulcer edge.

The fear of severe dumping resulting from gastrectomy must be balanced against the risk of episodic diarrhoea after vagotomy and drainage. Two of our patients, each with a truncal vagotomy and pyloroplasty, developed severe diarrhoea, sufficiently severe in one to require two further operations. With the adoption of selective vagotomy this problem may be reduced. The present series of patients has not yet been followed up long enough for us to make any observations on the long-term nutritional status.

\section{Conclusions}

Vagotomy and drainage, preferably selective vagotomy, is a satisfactory operation for gastric ulcers of types II and III in either sex, provided that cancer can be absolutely excluded by four-quadrant biopsy or complete excision of the ulcer edge with frozen-section histology. The results in men are comparable with those obtained when the same operation is performed for duodenal ulcer. In type I ulcers in women the recurrence rate is unacceptably high and Billroth I gastrectomy is to be preferred. In men with very high type I ulcers and normal levels of gastric acidity the operation may be used with caution if the site of the ulcer or age of the patient would make gastrectomy a difficult and dangerous procedure, but it should be avoided if acid secretion is reduced and gastric emptying is rapid.

\section{References}

Burge, H. (1966). Annals of the Royal College of Surgeons of England, 38, 439. Capper, W. M. (1967). Annals of the Royal College of Surgeons of England, 40,21

Douglas, M. C., and Duthie, H. L. (1971). British fournal of Surgery, 58, 721. Dragstedt, L. R. (1956). Gastroenterology, 30, 208.

Duthie, H. L. (1970). Gut, 11, 540.

Duthie, H. L., Moore, K. T. H., Bardsley, D., and Clark, R. G. (1970), British fournal of Surgery, 57, 784.

Farris, J. M., and Smith, G. K. (1966). Surgical Clinics of North America, 46,329 .

George, J. D. (1968). Gut, 9, 237.

George, J. D., Kennedy, T., and Connell, A. M. (1967). Gut, 8, 632.

Hendry, W. G., and Bahrani, S. A. (1965). British fournal of Surgery, 52, 588. Johnson, H. D., Love, A. H. G., Rogers, N. C., and Wyatt, A. P. (1964).

Gut, 5, 402 .
Kraft, R. O., Myers, J., Overton, S., and Fry, W. J. (1971). American fournal of Surgery, i21, 122 .

de Miguel, J. (1970). British fournal of Surgery, 57, 338.

Sawyers, J. L., Scott, H. W., and Graham, C. (1971). American fournal of Surgers. L., Scott, H.

Stemmer, E. A., Zahn, R. L., Horn, L. W., and Connolly, J. E. (1968), Archives of Surgery, 96, 586

Wasunna, A. E. O., Kennedy, F., Gillespie, I. E., and Kay, A. W. (1971). Lancet, 1, 722 .

Woodward, E. R., Eisenberg, M. M., and Dragstedt, L. R. (1967). American Fournal of Surgery, 113, 5 . 